\title{
Impact of piglet birthweight and sow parity on mortality rates, growth performance, and carcass traits in pigs
}

\author{
Everson Zotti ${ }^{1 *}$, Fábio Arnhold Resmini ${ }^{1}$, Luis Gustavo Schutz ${ }^{1}$, Nilson Volz ${ }^{1}$, Raul Pelissari \\ Milani ${ }^{1}$, Ana Maria Bridi ${ }^{2}$, Amauri Alcindo Alfieri ${ }^{3}$, Caio Abércio da Silva ${ }^{2}$
}

\author{
${ }^{1}$ Pontifícia Universidade Católica do Paraná, Departamento de Medicina Veterinária, Toledo, PR, Brazil. \\ 2 Universidade Estadual de Londrina, Departamento de Zootecnia, Londrina, PR, Brazil. \\ ${ }^{3}$ Universidade Estadual de Londrina, Departamento de Medicina Veterinária Preventiva, Londrina, PR, Brazil.
}

\begin{abstract}
A total of 5502 piglets from 435 sows were selected for evaluation of the effect of piglet birthweight and sow parity on mortality rate (MR), growth performance, and carcass traits in pigs. Piglets were distributed into one of eight categories according to their weight $(<600,601-800,801-1000,1001-1200,1201-1400,1401-1600,1601-1800$, and $>1801 \mathrm{~g})$ and sows were classified according to parity (1-5). The maximum MR during lactation (day 0 to day 21) was found in category $<600 \mathrm{~g}$, whereas the lowest was observed in categories $\geq 1401 \mathrm{~g}$. Pigs with greater body weight (BW) at birth were equivalently greater until 59 days of age. Average daily weight gain (ADG) was improved by increasing piglet birthweight between 0 and 21 days as indicated by a linear regression effect. After weaning, this effect was reduced up to 168 days, indicated by a quadratic, as opposed to linear, regression effect. The increase in growth rates corresponded to improved lean meat content and hot carcass weight. Increasing sow parity corresponded to a quadratic improvement of BW and ADG during lactation, but not after weaning. However, the improved pre-weaning performance was concomitant with a linear increase of within-litter BW and ADG variation. No effect of parity was observed on carcass traits. Piglet birthweight and sow parity influence litter postnatal development, mainly during early life. After weaning, these effects are less evident with a minor impact on carcass traits.
\end{abstract}

Key Words: carcass quality, growth curve, maternal effect, pig production, swine

\section{Introduction}

Despite technological advances in intensive pig production, low body weight (BW) at birth and high within-litter variation are two of the most important factors impairing profitability in the swine production chain. The increased litter size achieved in recent decades has been unfavorably correlated with piglet birthweight and withinlitter homogeneity (Knol et al., 2001; Quinton, et al., 2006; Wolf et al., 2008; Kim et al., 2009). These conditions have been shown to have significant effects on piglet subsequent mortality rate (MR), growth performance, carcass, and meat quality traits (Quiniou et al., 2002; Rehfeldt and Kuhn, 2006; Bérard et al., 2010; Fix et al., 2010a). However,

Received: December 2, 2016

Accepted: July 21, 2017

*Corresponding author: everson.zotti@gmail.com

http://dx.doi.org/10.1590/S1806-92902017001100004

How to cite: Zotti, E.; Resmini, F. A.; Schutz, L. G.; Volz, N.; Milani, R. P.; Bridi, A. M.; Alfieri, A. A. and Silva, C. A. 2017. Impact of piglet birthweight and sow parity on mortality rates, growth performance, and carcass traits in pigs. Revista Brasileira de Zootecnia 46(11):856-862.

Copyright (C) 2017 Sociedade Brasileira de Zootecnia. This is an Open Access article distributed under the terms of the Creative Commons Attribution License (http://creativecommons.org/licenses/by/4.0/), which permits unrestricted use, distribution, and reproduction in any medium, provided the original work is properly cited. considering that most of these studies were performed under stringent experimental conditions in controlled environments, their results may not be suitable for pig husbandry operations that do not meet these conditions. In this sense, it is worth mentioning that pig husbandry operations in Brazil have particular facility designs, such as open walls to dissipate heat during the hot season, allowing moderate room temperature variations throughout the day. Therefore, the use of a Brazilian conventional commercial facility, with non-controlled environmental conditions, as an experimental model would add new insight to this subject.

Among the causes of low birthweight and high withinlitter heterogeneity, sow parity is of particular interest. The physiological differences between low- and high-parity sows are known to affect piglet prenatal development (Foxcroft and Town, 2004; Silva et al., 2013). However, the impact of parity on piglet postnatal development, mortality rates, and carcass traits is not well understood. This lack of information limits the development of new strategies to prevent low postnatal growth and to control within-litter variations.

The objectives of this study were to evaluate the effects of piglet birthweight on mortality rate, growth performance, and carcass quality and assess the impact of 
sow parity on piglet birthweight and its variation, as well as on mortality rates, postnatal development, and carcass traits, under commercial conditions.

\section{Material and Methods}

Animals were used and cared for in accordance with the Committee on Ethics in Animal Use (CEUA) (case no. 26368.2012.23).

For eleven months, 5502 piglets (Topigs Tybor $\times$ Topigs 20) were selected at birth, all born through noninduced deliveries from 435 multiparous sows (Topigs 20; parity 1 to 5) housed in a commercial pig husbandry in Brazil. Five days prior to the predicted delivery day, sows were transferred to suspended maternity pens equipped with plastic flooring for sows and underfloor heating and incandescent lighting for piglets. Only curtains were used to control the room temperature. Average annual temperatures range from 13 to $25^{\circ} \mathrm{C}$.

For the study of sow parity, a total of $99,82,89,77$, and 78 sows of parity 1 to 5 were selected, respectively. For the study of piglet BW at birth, all piglets were identified by placing a tattoo, then individually weighed, and distributed into one out of the following eight weight categories: $<600$, 601-800, 801-1000, 1001-1200, 1201-1400, 1401-1600, 1601-1800, and $>1801 \mathrm{~g}$, with different frequencies in each category. Cross-fostering was performed only after the first 18-h postnatal period, in which sows of similar parity had their litters standardized by size, individual piglet weight, and age. Supplementary colostrum was not used for piglets in any weight category. Traditional handling procedures were performed during lactation and all animals had free access to water and feed. Individual birthweight, gender, mortality rate (MR), average daily weight gain (ADG), body weight at 7 (BW-7), 21 (BW-21), and 59 (BW-59) days of age of the piglets, and sow parity were recorded. Dead animals were also weighed individually to allow correction on ADG values.

At weaning ( $21 \pm 1.56$ days of age), piglets were transferred and housed (50 pigs per pen) in nursery barns consisting of 50 pens, which were located at the same pig breeding facility. Pigs were classified visually according to their BW as light-, medium-, or heavy-weight pigs. The nursery pens had suspended plastic flooring, gas heating, nipple drinkers, and an automatic group-feeding system. Feed composition followed the NRC (1998) recommendations. At $60 \pm 2.56$ days of age, piglets were transported to one of ten different finishers, where they were classified visually according to gender and $\mathrm{BW}$ as light-, medium-, or heavy-weight pigs, and were raised until slaughter ( $168 \pm 4.1$ days of age). Finishing pens had the capacity to house ten animals and were equipped with nipple drinkers and a manual group-feeding system with $33 \mathrm{~cm}$ of length per animal. Pigs were fed four times a day according to a nutritional plan. Only curtains were used to control the room temperature. All finisher farms followed a standardized handling procedure. At 168 days of age, all animals were slaughtered. Feed was withdrawn for a minimum of $16 \mathrm{~h}$ prior to transport and all pigs were fasted for a minimum of $4 \mathrm{~h}$ at the slaughter plant. After slaughter, hot carcass weight (HCW-168) was recorded and backfat depth (BD) and lean meat content (LMC) were determined using a SKF Ultra Form 300 probe (SKF do Brasil, Cajamar, São Paulo, Brazil) immediately before chilling.

Due to the commercial characteristics of the pig husbandry used in this experiment, some animals were missing during specific periods. The data for these animals were excluded from the statistical analysis for the specific period when they were missing. Mortality rate calculations were based strictly on the number of dead animals; no missing animals were included in this statistics.

Data were analyzed using the SAS (Statistical Analysis System, version 12.1) procedure for mixed models according to a randomized block design with unequal frequencies, with parity or birthweight category as the main independent variables. For the analyses in which birthweight category was the independent variable, parity was considered as a block. The model was: $\mathrm{Y}_{\mathrm{ij}}=\mu+\mathrm{J}_{\mathrm{i}}+\mathrm{e}_{\mathrm{ij}}$, in which $\mathrm{Y}_{\mathrm{ij}}=$ dependent variable, $\mu=$ general mean, $\mathrm{J}_{\mathrm{i}}=$ parity or birthweight category, and $\mathrm{e}_{\mathrm{ij}}=$ residual error. For the whole experimental period, the individual sow (litter average) was the experimental unit to evaluate parity effects and the individual pig was used as the experimental unit to evaluate birthweight effects. Regression analyses were performed to evaluate the effects of parity and birthweight categories. Data that did not allow parametric analysis were analyzed using the chi-squared test or Fisher's exact test. Differences were considered significant at $\mathrm{P} \leq 0.05$ and tendencies at $0.05<\mathrm{P} \leq 0.10$.

\section{Results}

Mortality rate in all piglet weight categories during the entire experimental period (0-168 days) was $11.1 \%$. The highest MR was observed during the lactation period $(9.7 \%)$ and $6.2 \%$ of piglets died during the first seven days of life. 
The maximum MR at 7 and 21 days was observed in the weight category $<600 \mathrm{~g}$, whereas categories $\geq 1401$ $\mathrm{g}$ had the lowest MR (Table 1). During the nursery and growing/finishing periods, no differences were found for MR ( $\mathrm{P}>0.05)$. However, when considering the overall experimental period, MR followed a similar pattern to those observed before weaning, particularly from piglets in weight categories $<600 \mathrm{~g}$ to 1201-1400 g (Table 1).

Out of the 5502 piglets born alive (Table 1), 17.5\% were born weighing $\leq 1000 \mathrm{~g}, 60.5 \%$ between 1001 and $1600 \mathrm{~g}$, and $22.0 \%$ weighed $\geq 1601 \mathrm{~g}$. The average weights on BW-7, BW-21, and BW-59 were $2.35 \pm 0.59,5.45 \pm 1.25$, and $20.61 \pm 3.86 \mathrm{~kg}$, respectively (Table 2). In all periods (7, 21, and 59 days of age), piglet BW improved with increasing birthweight category, leading to a positive linear effect of birthweight on BW-7 $(\mathrm{P}<0.01), \mathrm{BW}-21(\mathrm{P}<0.05)$, and BW-59 $(\mathrm{P}<0.05)$ (Table 2).

The ADG from 0 to 21,21 to 59,59 to 168 days of age, and during the overall experimental period (0-168 days of age) were $0.19 \pm 0.06,0.38 \pm 0.09,0.76 \pm 0.08$, and $0.49 \pm 0.05 \mathrm{~g}$, respectively (Table 3 ). From 0 to 21 days of age, the ADG improved with increasing piglet birthweight category, leading to a positive linear effect $(\mathrm{P}<0.01)$ (Table 3$)$. Additionally, quadratic effects of birthweight were observed on ADG for 21-59 $(\mathrm{P}<0.01)$ and 59-168 days $(\mathrm{P}<0.05)$, as well as for the whole experimental period (0-168 days of age) $(\mathrm{P}<0.01$; Table 3$)$.

Compared with the heaviest $(>1801 \mathrm{~g}$ ) piglet birthweight categories, ADG for the lightest piglets $(<600 \mathrm{~g})$ was lower by $28.8,30.1$, and $10.6 \%$ at suckling, post-weaning, and growing/finishing periods, respectively. The overall average $\mathrm{HCW}-168, \mathrm{BD}$, and $\mathrm{LMC}$ were $82.98 \pm 8.94 \mathrm{~kg}$, $14.87 \pm 3.78 \mathrm{~mm}$, and $57.6 \pm 6.3 \%$, respectively (Table 4). A quadratic effect of birthweight category on HCW-168 $(\mathrm{P}<0.01)$ (Table 4) was found, in which heavier piglets at birth were heavier at slaughter. Additionally, among hot carcasses weighing $>85 \mathrm{~kg}, 59.1 \%$ were observed in birthweight categories $\geq 1401 \mathrm{~g}(\mathrm{P}<0.05)$ and only $23.9 \%$ in those weighing $\leq 1000 \mathrm{~g}$ at birth. Although lighter at slaughter, a catch-up growth was observed for the lightest group (birthweight $<600 \mathrm{~g}$ ) compared with the heaviest (birthweight $>1801 \mathrm{~g})$. Pigs born weighing $<600 \mathrm{~g}$ were, on average, 2.54 times lighter at seven days of age and this difference was reduced to $1.72,1.52$, and 1.13 at 21 and 59 days of age and at slaughter, respectively.

Table 1 - Effect of piglet birthweight on mortality rate (MR), total and percentage, from birth to slaughter

\begin{tabular}{|c|c|c|c|c|c|c|c|c|c|c|c|}
\hline \multirow{2}{*}{ Category } & \multirow{2}{*}{$\frac{\text { Born alive }}{\mathrm{n}}$} & \multicolumn{2}{|c|}{ MR 0-7 days } & \multicolumn{2}{|c|}{ MR 0-21 days } & \multicolumn{2}{|c|}{ MR 21-59 days } & \multicolumn{2}{|c|}{ MR 59-168 days } & \multicolumn{2}{|c|}{ MR 0-168 days } \\
\hline & & $\mathrm{n}$ & $\%$ & $\mathrm{n}$ & $\%$ & $\mathrm{n}$ & $\%$ & $\mathrm{n}$ & $\%$ & $\mathrm{n}$ & $\%$ \\
\hline$<600$ & 82 & 31 & $37.8 \mathrm{a}$ & 41 & $50.0 \mathrm{a}$ & 1 & 2.4 & 0 & 0.0 & 42 & $51.2 \mathrm{a}$ \\
\hline $601-800$ & 266 & 50 & $18.8 \mathrm{~b}$ & 76 & $28.6 b$ & 6 & 3.2 & 0 & 0.0 & 82 & $30.8 b$ \\
\hline 801-1000 & 617 & 60 & $9.7 \mathrm{c}$ & 105 & $17.0 \mathrm{c}$ & 6 & 1.2 & 3 & 0.6 & 114 & $18.5 c$ \\
\hline $1001-1200$ & 982 & 60 & $6.1 d$ & 87 & $8.9 \mathrm{~d}$ & 8 & 0.9 & 4 & 0.5 & 99 & $10.1 d$ \\
\hline $1201-1400$ & 1259 & 64 & $5.1 \mathrm{de}$ & 102 & $8.1 \mathrm{de}$ & 12 & 1.0 & 3 & 0.3 & 117 & $9.3 \mathrm{de}$ \\
\hline $1401-1600$ & 1086 & 37 & $3.4 \mathrm{ef}$ & 61 & $5.6 \mathrm{ef}$ & 14 & 1.4 & 4 & 0.4 & 79 & $7.3 \mathrm{de}$ \\
\hline $1601-1800$ & 753 & 25 & $3.3 \mathrm{ef}$ & 39 & $5.2 \mathrm{f}$ & 6 & 0.8 & 2 & 0.3 & 47 & $6.2 \mathrm{e}$ \\
\hline$>1801$ & 457 & 12 & $2.6 f$ & 21 & $4.6 f$ & 6 & 1.4 & 4 & 0.9 & 31 & $6.8 \mathrm{de}$ \\
\hline Total & 5502 & 339 & - & 532 & - & 59 & - & 20 & - & 611 & - \\
\hline
\end{tabular}

a-f - Differences between means in the column with different letters are significant by the Fisher's exact test $(\mathrm{P}<0.05)$.

Table 2 - Effect of piglet birthweight on piglet body weight at 7 (BW-7), 21 (BW-21), and 59 (BW-59) days of age

\begin{tabular}{|c|c|c|c|c|c|c|}
\hline Category & n 7 days & BW-7 (kg) ${ }^{1}$ & n 21 days & BW-21 (kg) ${ }^{2}$ & n 59 days & BW-59 $(\mathrm{kg})^{3}$ \\
\hline$<600$ & 39 & $1.20 \mathrm{~h}$ & 36 & $3.73 \mathrm{~g}$ & 35 & $15.24 \mathrm{~g}$ \\
\hline $601-800$ & 199 & $1.49 \mathrm{~g}$ & 177 & $4.17 \mathrm{~g}$ & 164 & $16.62 \mathrm{~g}$ \\
\hline $801-1000$ & 524 & $1.78 \mathrm{f}$ & 491 & $4.69 \mathrm{f}$ & 463 & $18.48 \mathrm{f}$ \\
\hline $1001-1200$ & 891 & $2.06 \mathrm{e}$ & 854 & $5.07 \mathrm{e}$ & 823 & $19.52 \mathrm{e}$ \\
\hline $1201-1400$ & 1167 & $2.31 \mathrm{~d}$ & 1115 & $5.35 \mathrm{~d}$ & 1067 & $20.54 d$ \\
\hline $1401-1600$ & 1029 & $2.55 \mathrm{c}$ & 988 & $5.76 \mathrm{c}$ & 946 & $21.37 \mathrm{c}$ \\
\hline $1601-1800$ & 708 & $2.78 \mathrm{~b}$ & 680 & $6.05 \mathrm{~b}$ & 669 & $22.20 \mathrm{~b}$ \\
\hline$>1801$ & 436 & $3.05 \mathrm{a}$ & 407 & $6.41 \mathrm{a}$ & 405 & $23.09 \mathrm{a}$ \\
\hline SEM & - & 0.59 & - & 1.25 & - & 3.86 \\
\hline P-value & - & $<0.01$ & - & $<0.05$ & - & $<0.05$ \\
\hline
\end{tabular}

SEM - standard error of the mean.

${ }^{1}$ Within a column, there is a linear effect as birthweight increases $\left(\mathrm{y}=0.652431+0.00126385 \mathrm{x} ; \mathrm{R}^{2}=1.00 ; \mathrm{P}<0.01\right)$.

${ }^{2}$ Within a column, there is a linear effect as birthweight increases $\left(\mathrm{y}=3.07264+0.00176795 \mathrm{x} ; \mathrm{R}^{2}=0.99 ; \mathrm{P}<0.05\right)$.

${ }^{3}$ Within a column, there is a linear effect as birthweight increases $\left(\mathrm{y}=14.0181+0.0048847 \mathrm{x}, \mathrm{R}^{2}=0.98 ; \mathrm{P}<0.05\right)$.

$\mathrm{a}-\mathrm{h}$ - Differences between means in the column with different letters are significant $(\mathrm{P}<0.01 ; \mathrm{P}<0.05)$. 
No difference for BD was observed (14.87 $\pm 3.78 \mathrm{~mm}$; $\mathrm{P}=0.24$ ) among birthweight categories, whereas a positive linear effect of birthweight category was found on LMC $(\mathrm{P}<0.01)$ (Table 4).

No effect of sow parity on MR was observed during any of the studied periods. Average values were $6.2 \%$ for 0-7 days, $9.7 \%$ for $0-21$ days, $1.2 \%$ for $21-59$ days, $0.4 \%$ for $59-168$ days, and $11.1 \%$ for $0-168$ days of age. The overall average number of piglets born alive was $12.72 \pm 3.26$ and a positive linear effect of parity was observed $(\mathrm{P}<0.01)$ (Table 5).

Piglet average weight at birth, BW-7, BW-21, and BW-59 were $1.36 \pm 0.21,2.37 \pm 0.36,5.46 \pm 0.69$, and $20.68 \pm 2.23$, respectively. No regression effect was observed on birthweight despite the significant effect of parity $(\mathrm{P}<0.05)$. However, a quadratic effect of parity on $\mathrm{BW}-7$ $(\mathrm{P}<0.01), \mathrm{BW}-21(\mathrm{P}<0.01)$, and BW-59 $(\mathrm{P}=0.06)$ (Table 5) was observed. Piglet average $\mathrm{BW}$ variation $(\mathrm{BW}-\mathrm{CV})$ at birth (BW-0 CV), 7, 21, and 59 days of age were 20.4 \pm 6.3 , $20.5 \pm 6.7,19.7 \pm 5.5$, and $16.1 \pm 5.5 \%$, respectively (Table 5).
Positive linear effects of parity on BW-0 CV $(\mathrm{P}<0.01)$, BW-7 CV $(\mathrm{P}<0.01)$, and BW-21 CV $(\mathrm{P}<0.01)$ (Table 5) were observed, but not for BW-59 CV $(\mathrm{P}=1.00)$.

The ADG from 0 to 21,21 to 59 , and 59 to 168 days of age and during the overall experimental period (0-168 days) were $0.12 \pm 0.03,0.40 \pm 0.05,0.77 \pm 0.05$, and $0.49 \pm 0.03$ g, respectively (Table 6). From 0 to 21 days of age, parity had a quadratic effect on $\mathrm{ADG}(\mathrm{P}<0.05)$ (Table 6), but no effect was observed from 21 to 59 days of age $(\mathrm{P}=0.18)$. During the growing-finishing phase (59-168 days of age) and considering the whole experimental period (0-168 days of age), no regression effect was found, despite a significant effect of parity on ADG $(\mathrm{P}<0.05)$. Average ADG variation (ADG-CV) from 0-21, 21-59, 59-168 days of age, and during the overall experimental period (0-168 days) were $30.5 \pm 8.5 \%, 19.1 \pm 7.6 \%, 8.9 \pm 3.7 \%$, and $9.1 \pm 3.6 \%$, respectively (Table 6). Parity had a positive linear effect on ADG-CV from 0 to 21 days of age $(\mathrm{P}<0.05)$ (Table 6), but not for any other periods $(\mathrm{P} \geq 0.18)$.

The overall average $\mathrm{HCW}-168, \mathrm{BD}$, and $\mathrm{LMC}$ were $84.01 \pm 5.58 \mathrm{~kg}, 14.92 \pm 2.04 \mathrm{~mm}$, and $57.8 \pm 3.1 \%$,

Table 3 - Effect of piglet birthweight on average daily gain (ADG) from birth to slaughter

\begin{tabular}{|c|c|c|c|c|c|c|c|c|}
\hline \multirow{2}{*}{ Category } & \multicolumn{2}{|c|}{ 0-21 days } & \multicolumn{2}{|c|}{ 21-59 days } & \multicolumn{2}{|c|}{ 59-168 days } & \multicolumn{2}{|c|}{$0-168$ days } \\
\hline & $\mathrm{n}$ & $\mathrm{ADG}(\mathrm{kg})^{1}$ & $\mathrm{n}$ & $\mathrm{ADG}(\mathrm{kg})^{2}$ & $\mathrm{n}$ & $\operatorname{ADG}(\mathrm{kg})^{3}$ & $\mathrm{n}$ & $\operatorname{ADG}(\mathrm{kg})^{4}$ \\
\hline$<600$ & 36 & $0.15 \mathrm{~d}$ & 33 & $0.31 \mathrm{e}$ & 19 & $0.71 \mathrm{f}$ & 21 & $0.461 \mathrm{e}$ \\
\hline $601-800$ & 177 & $0.17 \mathrm{~d}$ & 158 & $0.32 \mathrm{e}$ & 111 & $0.70 \mathrm{def}$ & 121 & $0.46 \mathrm{cde}$ \\
\hline 801-1000 & 491 & $0.18 \mathrm{c}$ & 449 & $0.36 \mathrm{~d}$ & 289 & $0.73 \mathrm{e}$ & 317 & $0.47 \mathrm{~d}$ \\
\hline $1001-1200$ & 854 & $0.19 b c$ & 795 & $0.38 \mathrm{c}$ & 517 & $0.75 d$ & 564 & $0.49 \mathrm{c}$ \\
\hline $1201-1400$ & 1115 & $0.19 b$ & 1037 & $0.40 \mathrm{~b}$ & 649 & $0.77 \mathrm{c}$ & 708 & $0.50 \mathrm{~b}$ \\
\hline $1401-1600$ & 988 & $0.20 \mathrm{a}$ & 921 & $0.41 b$ & 589 & $0.78 \mathrm{~b}$ & 634 & $0.50 \mathrm{ab}$ \\
\hline $1601-1800$ & 680 & $0.21 \mathrm{a}$ & 641 & $0.42 \mathrm{a}$ & 415 & $0.79 \mathrm{ab}$ & 444 & $0.51 \mathrm{a}$ \\
\hline$>1801$ & 407 & $0.21 \mathrm{a}$ & 385 & $0.44 \mathrm{a}$ & 234 & $0.80 \mathrm{a}$ & 251 & $0.51 \mathrm{a}$ \\
\hline SEM & - & 0.06 & - & 0.09 & - & 0.08 & - & 0.05 \\
\hline
\end{tabular}

SEM - standard error of the mean.

${ }^{1}$ Within a column, there is a linear effect as birthweight increases $(y=0.143752+0.0000376777 \mathrm{x} ; \mathrm{R}=0.97 ; \mathrm{P}<0.01)$.

${ }^{2}$ Within a column, there is a quadratic effect as birthweight increases $\left(y=0.226473+0.000180388 x-0.000000037078 x^{2} ; R^{2}=0.99 ; P<0.01\right)$.

${ }^{3}$ Within a column, there is a quadratic effect as birthweight increases $\left(\mathrm{y}=0.615628+0.000160014 \mathrm{x}-0.0000000330603 \mathrm{x}^{2} ; \mathrm{R}^{2}=0.98 ; \mathrm{P}<0.05\right)$.

${ }^{4}$ Within a column, there is a quadratic effect as birthweight increases $\left(\mathrm{y}=0.402945+0.0000979284 \mathrm{x}-0.0000000212952 \mathrm{x}^{2} ; \mathrm{R}^{2}=0.99 ; \mathrm{P}<0.01\right)$.

a-f - Differences between means in the column with different letters are significant.

Table 4 - Effect of piglet birthweight on hot carcass weight at 168 days of age (HCW-168), carcasses heavier than $85 \mathrm{~kg}$ at slaughter, backfat depth (BD), and lean meat content (LMC)

\begin{tabular}{|c|c|c|c|c|c|}
\hline Category & n 168 days & HCW-168 (kg) ${ }^{1}$ & Carcass $>85 \mathrm{~kg}(\%)^{2}$ & $\mathrm{BD}(\mathrm{mm})$ & $\operatorname{LMC}(\%)^{3}$ \\
\hline$<600$ & 21 & $78.01 \mathrm{def}$ & $23.8 \mathrm{~d}$ & 14.24 & $55.9 \mathrm{abc}$ \\
\hline $601-800$ & 121 & $77.63 \mathrm{f}$ & $19.0 \mathrm{~d}$ & 15.54 & $56.3 c$ \\
\hline $801-1000$ & 317 & $80.50 \mathrm{e}$ & $28.4 d$ & 14.52 & $57.7 \mathrm{abc}$ \\
\hline $1001-1200$ & 564 & $82.53 d$ & $37.8 \mathrm{c}$ & 14.94 & $57.9 \mathrm{abc}$ \\
\hline $1201-1400$ & 708 & $84.45 c$ & $48.3 b$ & 15.02 & $57.6 \mathrm{bc}$ \\
\hline $1401-1600$ & 634 & $85.74 b c$ & $55.8 \mathrm{a}$ & 15.06 & $58.4 \mathrm{ab}$ \\
\hline $1601-1800$ & 444 & $87.19 \mathrm{ab}$ & $60.1 \mathrm{a}$ & 14.87 & $58.7 \mathrm{a}$ \\
\hline$>1801$ & 251 & $87.82 \mathrm{a}$ & $61.4 \mathrm{a}$ & 14.78 & $58.3 \mathrm{abc}$ \\
\hline SEM & & 8.94 & - & 3.78 & 6.3 \\
\hline P-value & - & $<0.01$ & $<0.05$ & 0.24 & $<0.01$ \\
\hline
\end{tabular}

SEM - standard error of the mean.

${ }^{1}$ Within a column, there is a quadratic effect as birthweight increases $\left(\mathrm{y}=67.8432+0.0172351 \mathrm{x}-0.00000349537 \mathrm{x}^{2} ; \mathrm{R}^{2}=0.99 ; \mathrm{P}<0.01\right)$

2 a-d - Differences between means in the column with different letters are significant by the chi-squared test $(\mathrm{P}<0.05)$.

${ }^{3}$ Within a column, there is a linear effect as birthweight increases $(\mathrm{y}=56.18+0.00134315 \mathrm{x} ; \mathrm{R}=0.61 ; \mathrm{P}<0.01)$. 
respectively (Table 7). Although the effect of parity on HCW-168 was significant $(\mathrm{P}<0.05)$, no regression effect was found. Similar to the results for BW-59, a relatively narrow range of weights was observed at slaughter $(82.33 \pm 5.58$ to $84.94 \pm 5.58 \mathrm{~kg}$ ). Analyzing this data (Table 7) from another standpoint ( $\%$ carcass $>85 \mathrm{~kg}$ ), parity 2 had the heaviest carcasses whereas parity 1 and 4 had the lowest percentage of heavy carcasses $(\mathrm{P}<0.05)$.
No regression effect was observed for $\mathrm{LMC}$, despite a significant effect of parity $(\mathrm{P}<0.01)$. For $\mathrm{BD}$, a quadratic effect of parity was found $(\mathrm{y}=13.7468+0.913812 \mathrm{x}-$ $\left.0.142904 \mathrm{x}^{2} ; \mathrm{R}^{2}=0.78 ; \mathrm{P}=0.06\right)$. Variation of HCW, BD (BD-CV), and LMC (LMC-CV) were 8.9 $\pm 3.6,22.3 \pm 8.6$, and $10.4 \pm 4.2 \%$, respectively (Table 7 ). No effect of parity was found on $\mathrm{HCW}-168 \mathrm{CV}(\mathrm{P}=0.26)$, BD-CV $(\mathrm{P}=0.12)$, and LMC-CV $(\mathrm{P}=0.10)$.

Table 5 - Effect of sow parity on the number of piglets born alive, piglet BW and BW variation at birth (BW-0 CV), 7 (BW-7 CV), 21 (BW-21 CV), and 59 (BW-59 CV) days of age

\begin{tabular}{|c|c|c|c|c|c|c|c|c|c|}
\hline \multirow{2}{*}{ Parity } & \multirow{2}{*}{ Born alive $^{1}$} & \multicolumn{2}{|c|}{0 day } & \multicolumn{2}{|c|}{7 days } & \multicolumn{2}{|c|}{21 days } & \multicolumn{2}{|c|}{59 days } \\
\hline & & BW $(\mathrm{kg})$ & $\mathrm{CV}(\%)^{2}$ & $\mathrm{BW}(\mathrm{kg})^{3}$ & $\mathrm{CV}(\%)^{4}$ & $\mathrm{BW}(\mathrm{kg})^{5}$ & $\mathrm{CV}(\%)^{6}$ & $\mathrm{BW}(\mathrm{kg})^{7}$ & CV (\%) \\
\hline 1 & 11.9 & 1.33 & $17.1 \mathrm{c}$ & 2.31 & $16.9 \mathrm{~b}$ & 5.16 & 16.9 & 20.25 & 16.4 \\
\hline 2 & 11.6 & 1.42 & $19.7 b$ & 2.51 & $18.5 b$ & 5.57 & 19.2 & 21.07 & 15.8 \\
\hline 3 & 13.3 & 1.35 & $21.2 \mathrm{ab}$ & 2.36 & $22.0 \mathrm{a}$ & 5.53 & 20.3 & 21.00 & 15.5 \\
\hline 4 & 13.4 & 1.33 & $21.5 \mathrm{ab}$ & 2.36 & $21.8 \mathrm{a}$ & 5.58 & 20.2 & 20.42 & 16.1 \\
\hline 5 & 13.4 & 1.36 & $22.5 \mathrm{a}$ & 2.31 & $23.3 \mathrm{a}$ & 5.48 & 21.7 & 20.67 & 16.8 \\
\hline SEM & 3.26 & 0.21 & 6.3 & 0.36 & 6.7 & 0.69 & 6.5 & 2.23 & 5.5 \\
\hline P-value & $<0.01$ & $<0.05$ & $<0.01$ & $<0.01$ & $<0.01$ & $<0.01$ & $<0.01$ & 0.06 & 1.00 \\
\hline
\end{tabular}

BW - body weight; CV - coefficient of variation; SEM - standard error of the mean.

${ }^{1}$ Within a column, there is a linear effect as parity increases $\left(\mathrm{y}=11.3343+0.466546 \mathrm{x} ; \mathrm{R}^{2}=0.71 ; \mathrm{P}<0.01\right)$.

${ }^{2}$ Within a column, there is a linear effect as parity increases $\left(y=16.4614+1.30835 \mathrm{x} ; \mathrm{R}^{2}=0.90 ; \mathrm{P}<0.01\right)$.

${ }^{3}$ Within a column, there is a quadratic effect as parity increases $\left(\mathrm{y}=2.22465+0.144355 \mathrm{x}-0.0262341 \mathrm{x}^{2} ; \mathrm{R}^{2}=0.40 ; \mathrm{P}<0.01\right)$

${ }^{4}$ Within a column, there is a linear effect as parity increases $\left(y=15.6387+1.62569 \mathrm{x} ; \mathrm{R}^{2}=0.90 ; \mathrm{P}<0.01\right)$

${ }^{5}$ Within a column, there is a quadratic effect as parity increases $\left(\mathrm{y}=4.79374+0.467216 \mathrm{x}-0.0667481 \mathrm{x}^{2} ; \mathrm{R}^{2}=0.87 ; \mathrm{P}<0.01\right)$.

${ }^{6}$ Within a column, there is a linear effect as parity increases $\left(\mathrm{y}=16.3629+1.09681 \mathrm{x} ; \mathrm{R}^{2}=0.89 ; \mathrm{P}<0.01\right)$.

${ }^{7}$ Within a column, there is a quadratic effect as parity increases $\left(\mathrm{y}=19.7227+0.782882 \mathrm{x}-0.126494 \mathrm{x}^{2} ; \mathrm{R}^{2}=0.45 ; \mathrm{P}=0.06\right)$

$\mathrm{a}, \mathrm{b}, \mathrm{c}$ - Differences between means in the column with different letters are significant $(\mathrm{P}<0.01)$.

Table 6 - Effect of sow parity on average daily gain (ADG) and ADG variation (ADG-CV) from birth to slaughter

\begin{tabular}{|c|c|c|c|c|c|c|c|c|}
\hline \multirow{2}{*}{ Parity } & \multicolumn{2}{|c|}{$0-21$ days } & \multicolumn{2}{|c|}{ 21-59 days } & \multicolumn{2}{|c|}{ 59-168 days } & \multicolumn{2}{|c|}{$0-168$ days } \\
\hline & $\operatorname{ADG}(\mathrm{kg})^{1}$ & $\mathrm{CV}(\%)^{2}$ & $\mathrm{ADG}(\mathrm{kg})$ & CV (\%) & ADG $(\mathrm{kg})$ & CV (\%) & $\mathrm{ADG}(\mathrm{kg})$ & CV (\%) \\
\hline 1 & 0.18 & 21.9 & 0.40 & 19.6 & 0.77 & 8.9 & 0.49 & 8.9 \\
\hline 2 & 0.20 & 53.6 & 0.41 & 19.1 & 0.77 & 9.0 & 0.49 & 9.2 \\
\hline 3 & 0.20 & 25.2 & 0.41 & 18.0 & 0.78 & 8.7 & 0.50 & 9.0 \\
\hline 4 & 0.20 & 24.6 & 0.39 & 19.3 & 0.75 & 9.6 & 0.48 & 9.8 \\
\hline 5 & 0.19 & 27.0 & 0.40 & 19.6 & 0.77 & 8.3 & 0.49 & 8.4 \\
\hline SEM & 0.03 & 8.5 & 0.05 & 7.6 & 0.05 & 3.7 & 0.03 & 3.6 \\
\hline P-value & $<0.05$ & $<0.05$ & 0.18 & 1.00 & $<0.05$ & 0.25 & $<0.05$ & 0.23 \\
\hline
\end{tabular}

$\mathrm{CV}$ - coefficient of variation; SEM - standard error of the mean.

${ }^{1}$ Within a column, there is a quadratic effect as parity increases $\left(y=0.164680+0.0205789 x-0.00289833 \mathrm{x}^{2} ; \mathrm{R}^{2}=0.94 ; \mathrm{P}<0.05\right)$.

${ }^{2}$ Within a column, there is a linear effect as parity increases $\left(y=21.0420+1.13989 \mathrm{x} ; \mathrm{R}^{2}=0.88 ; \mathrm{P}<0.05\right)$.

Table 7 - Effect of sow parity on hot carcass weight (HCW-168) and variation (HCW-168 CV) at 168 days of age, carcasses heavier than $85 \mathrm{~kg}$, backfat depth (BD) and variation (BD-CV), and lean meat content (LMC) and variation (LMC-CV)

\begin{tabular}{|c|c|c|c|c|c|c|c|}
\hline Parity & HCW-168 (kg) & HCW-168 CV (\%) & Carcass $>85 \mathrm{~kg}(\%)^{1}$ & $\mathrm{BD}(\mathrm{mm})^{2}$ & BD-CV $(\%)$ & LMC (\%) & LMC-CV (\%) \\
\hline 1 & 84.09 & 8.8 & $49.9 \mathrm{bc}$ & 14.44 & 20.5 & 58.3 & 9.8 \\
\hline 2 & 84.41 & 9.1 & $50.5 \mathrm{c}$ & 15.26 & 24.0 & 57.2 & 10.7 \\
\hline 3 & 84.94 & 9.0 & $47.2 \mathrm{~b}$ & 15.04 & 22.1 & 58.3 & 10.2 \\
\hline 4 & 82.33 & 9.6 & $40.0 \mathrm{a}$ & 15.10 & 23.0 & 57.1 & 11.4 \\
\hline 5 & 84.27 & 8.4 & $48.3 b$ & 14.78 & 22.0 & 58.3 & 9.9 \\
\hline SEM & 5.58 & 3.6 & - & 2.04 & 8.6 & 3.1 & 4.2 \\
\hline P-value & $<0.05$ & 0.26 & $<0.05$ & 0.06 & 0.12 & $<0.01$ & 0.10 \\
\hline
\end{tabular}

$\mathrm{CV}$ - coefficient of variation; SEM - standard error of the mean.

${ }_{a}^{1}$,b,c - Differences between means in the column with different letters are significant by the chi-squared test $(\mathrm{P}<0.05)$.

${ }^{2}$ Within a column, there is a quadratic effect as parity increases $\left(\mathrm{y}=13.7468+0.913812 \mathrm{x}-0.142904 \mathrm{x}^{2} ; \mathrm{R}^{2}=0.78 ; \mathrm{P}=0.06\right)$. 


\section{Discussion}

Concerning MR, our results (Table 1) are in agreement with other studies (Gardner et al., 1989; Quiniou et al., 2002) that reported the lowest survival rates from birth to weaning in piglets weighing $<1 \mathrm{~kg}$ at birth. These authors also reported increased odds of survival from birth to weaning with increasing birthweight. Among the factors affecting MR up to slaughter age, neonatal mortality is the most important (Cronin et al., 2000; Marchant et al., 2000; Quiniou et al., 2002). According to Fix et al. (2010b), the main causes of death during early lactation are related to low vitality and energy intake due to insufficient colostrum intake, especially by light-birthweight piglets (Le Dividich et al., 2005; Devillers et al., 2007). These factors may have been the major contributors to the present MR because starvation was the main cause of death for up to 7 and 21 days of age (59.8 and 55.6\%, respectively; data not shown) among piglet categories $\leq 1000 \mathrm{~g}$ at birth.

The results of performance obtained (Tables 2 and 3) are consistent with previous studies (Powell and Aberle, 1980; Quiniou et al., 2002; Smith et al., 2007) in which lighter piglets at birth or at weaning remained lighter until slaughter. It has been known for many years that lightbirthweight piglets differ biologically from their heavier littermates. Among these differences, the smaller number of secondary muscle fibers (Wigmore and Stickland, 1983) and impaired intestinal development (Alvarenga et al., 2013) are likely to interfere with long-term growth.

Although birthweight category had a marked influence on $\mathrm{BW}$ of pigs in all periods, these effects on ADG decreased over time. The lower ADG during the lactation period observed in this study may be explained by lightbirthweight piglets that consume less milk per suckle than their heavier littermates (Le Dividich, 1999). However, during later periods, differences in growth performance among piglets in the various birthweight categories do not appear to be related to difference in food intake. In fact, to prevent possible interference of pig BW variation on feed intake (e.g., disputes for feeder space), during nursery and growing/finishing periods, pigs were selected and housed according to their BW. Moreover, feed allowance was predetermined by a nutritional plan and optimized by the feeder length, allowing all animals in a pen concomitant access to the feeder. Therefore, although feed was not provided ad libitum in this study, it is unlikely that light piglets had impaired feed intake compared with heavy piglets. Considering the intestinal morphological disturbance experienced by light-birthweight pigs, due to impairments of gene expression related to growth (Alvarenga et al., 2013), which is negatively correlated to piglet postnatal growth performance, it is reasonable to argue that physiological immaturity may have reduced intestinal digestive capacities, affecting the ADG of piglets.

In relation to the carcass results (Table 4), according to Alvarenga et al. (2013), under Brazilian commercial conditions, high-birthweight piglets (1800-2200 g) have better carcass yield than piglets weighing 800-1200 g at birth; however, Beaulieu et al. (2010) in Canada, did not find any differences for carcass quality between light- and heavy-birthweight piglets. In the present study, performed under Brazilian commercial conditions and comprising a large range of birthweight categories, piglet birthweight had a direct effect on LMC, but not on BD. It is noteworthy that data regarding the impact of birthweight category on carcass traits are inconsistent (Gondret et al., 2005, 2006), likely due to differences in feeding strategies, rearing conditions, and the range of piglet birthweight used between studies.

Considering de effect of sow parity on ADG and ADG-CV (Table 6), similarly, looking at this factor on birthweight, parity affected these parameters particularly during the lactation period. The higher volume of milk produced by older sows (Beyer et al., 2007) may explain the higher ADG in these categories during the lactation period. After weaning, however, environmental factors appear to prevail and account for the differences in ADG and ADG$\mathrm{CV}$ observed in the present study. Nevertheless, it cannot be ruled out that factors related to parity, such as the ones affecting gastrointestinal morphology (Alvarenga et al., 2013) and muscle fiber development (Silva et al., 2013), may not impair the postnatal performance of piglets.

Concerning the effects of sow parity on carcass parameters (Table 7), our results are consistent with those of Tang et al. (2008) for the effects of parity on BD and strengthen the known effect of BD of sows on litter BD at slaughter (Amdi et al., 2014).

\section{Conclusions}

Both piglet birthweight and sow parity affect piglet post-natal development, mainly during early life. Piglets can partially counteract the impairments of light birthweight on growth performance during the postnatal period.

\section{References}

Alvarenga, A. L N.; Chiarini-Garcia, H.; Cardeal, P. C.; Moreira, L. P.; Foxcroft, G. R.; Fontes, D. O. and Almeida, F. R. C. C. 2013. Intra-uterine growth retardation affects birth weight and postnatal 
development in pigs, impairing muscle accretion, duodenal mucosa morphology and carcass traits. Reproduction, Fertility and Development 25:387-395.

Amdi, C.; Giblin, L.; Ryan, T.; Stickland, N. C. and Lawlor, P. G. 2014. Maternal backfat depth in gestating sows has a greater influence on offspring growth and carcass lean yield than maternal feed allocation during gestation. Animal 8:236-244.

Beaulieu, A. D.; Aalhus, J. L.; Williams, N. H. and Patience, J. F. 2010. Impact of piglet birth weight, birth order and litter size on subsequent growth performance, carcass quality, muscle composition and eating quality of pork. Journal of Animal Science 88:2767-2778.

Bérard, J.; Pardo, C. E.; Bethaz, S. and Bee, G. 2010. Intrauterine crowding decreases average birth weight and affects muscle fibre hyperplasia in piglets. Journal of Animal Science 88:3242-3250.

Beyer, M.; Jentsch, W.; Kuhla, S. Wittenburg, H.; Kreienbring, F.; Scholze, H.; Rudolph, P. E. and Metges, C C. 2007. Effects of dietary energy intake during gestation and lactation on milk yield and composition of first, second and fourth parity sows. Archives of Animal Nutrition 61:452-468.

Cronin, G. M.; Lefébure, B. and McClintock, S. A. 2000. A comparison of piglet production and survival in the Werribee Farrowing Pen and conventional farrowing crates at a commercial farm. Australian Journal of Experimental Agriculture 40:17-23.

Devillers, N.; Farmer, C.; Le Dividich, J. and Prunier, A. 2007. Variability of colostrum yield and colostrum intake in pigs. Animal 1:1033-1041

Fix, J. S.; Cassady, J. P.; Herring, W. O.; Holl, J. W.; Culbertson, M. S. and See, M. T. 2010a. Effect of piglet birth weight on body weight, growth, backfat and longissimus muscle area of commercial market swine. Livestock Science 127:51-59.

Fix, J. S.; Cassady, J. P.; Holl, J. W.; Herring, W. O.; Culbertson, M. S. and See, M. T. 2010b. Effect of piglet birth weight on survival and quality of commercial swine. Livestock Science 132:98-106.

Foxcroft, G. R. and Town, S. 2004. Prenatal programming of postnatal performance - The unseen cause of variance. Advances in Pork Production 5:269-279.

Gardner, I. A.; Hird, D. W.and Franti, C. E. 1989. Neonatal survival in swine: Effects of low birth weight and clinical disease. American Journal of Veterinary Research 50:792-797.

Gondret, F.; Lefaucheur, L.; Louveaua, I.; Lebret, B.; Pichodo, X. and Le Cozler, Y. 2005. Influence of piglet birth weight on postnatal growth performance, tissue lipogenic capacity and muscle histological traits at market weight. Livestock Production Science 93:137-146.

Gondret, F.; Lefaucheur, L.; Juin, H.; Louveau I. and Lebret B. 2006. Low birth weight is associated with enlarged muscle fibre area and impaired meat tenderness of the longissimus muscle in pigs. Journal of Animal Science 84:93-103.
Kim, S. W.; Hurley, W. L. and Wu, G. 2009. Ideal amino acid balance for sows during gestation and lactation. Journal of Animal Science $87: 123-132$.

Knol, E. F.; Leenhouwersb, J. I. and Lende, Van Der T. 2001. Genetic aspects of piglet survival. Livestock Production Science 78:45-55.

Le Dividich, J. 1999. Neonatal and weaner pig: management to reduce variation, in manipulating pig production. p.135-156 In: 7th Biennial Conference of the Australian Pig Science Association, Adelaide.

Le Dividich, J.; Rooke, J. A. and Herpin, P. 2005. Nutritional and immunological importance of colostrum for the newborn pig. Journal of Agricultural Science 143:469-485.

Marchant, J. N.; Rudd, A. R.; Mendl, M. T.; Broom, D. M,; Meredith, M. J.; Corning, S. and Simmins P. H. 2000. Timing and causes of piglet mortality in alternative and conventional farrowing systems. Veterinary Record 147:209-214.

NRC - National Research Council. 1998. Nutrient requirements of swine. 10th ed. National Academy Press, Washington DC.

Powell, S. E. and Aberle, E. D. 1980. Effects of birth weight on growth and carcass composition of swine. Journal of Animal Science 50:860-868.

Quiniou, N.; Dagorn, J. and Gaudre, D. 2002. Variation of piglets' birth weight and consequences on subsequent performance. Livestock Production Science 78:63-70.

Quinton, V. M.; Wilton, J. W.; Robinson, J. A. and Mathur, P. K. 2006. Economic weights for sow productivity traits in nucleus pig populations. Livestock Science 99:69-77.

Rehfeldt, C. and Kuhn, G. 2006, Consequences of birth weight for postnatal growth performances and carcass quality in pigs as related to myogenesis. Journal of Animal Science 84:113-123.

Silva, A. A.; Dalto, D. B.; Lozano, A.; Oliveira, E. R.; Gavioli, D.; Oliveira, J.; Romero, N., and Silva, C. A. 2013. Differences in muscle characteristics of piglets related to the sow parity. Canadian Journal of Animal Science 93:471-475.

Smith, A. L.; Stalder, K. J.; Serenius, T. V.; Baas, T. J. and Mabry, J. W. 2007. Effect of piglet birth weight on weights at weaning and 42 days post weaning. Journal of Swine Health and Production $15: 213-218$

Tang, Z.; Peng, Z.; Liu, B.; Fan, B.; Zhao, S,; Li, X.; Xu, S. and Li, K. 2008. Effect of breed, sex and birth parity on growth, carcass and meat quality in pigs. Frontiers of Agriculture in China 2:331-337.

Wigmore, P. M. C. and Stickland, N. C. 1983. Muscle development in large and small fetuses. Journal of Anatomy 137:235-245.

Wolf, J.; Zakova, E. and Groeneveld, E. 2008. Within-litter variation of birth weight in hyperprolific Czech Large White sows and its relation to litter size traits, still born piglets and losses until weaning. Livestock Production Science 115:195-205. 